\begin{abstract}
e एकe एकe
Титова B.H.,

кандидат юридических наук, доцент, профессор кафедры прокурорского надзора за исполнением законов в ОРД и участия прокурора в уголовном судопроизводстве Академии Генеральной прокуратуры РФ E-mail: vt3013607@yandex.ru

Аннотация. В статье рассматриваются причины значительного сокращения уголовных дел о налоговых преступлениях, направленных в суд с обвинительным заключением, и низкого уровня возмещения ущерба, причиненного данной категорией преступлений, вносятся конкретные предложения по совершенствованию действуюшего законодательства для изменения ситуации.

Ключевые слова: налоговые органы, следователь, налоговое и уголовное законодательство, возмещение ущерба, прокурор, изменение кониепици законодательства в сфере налогообложения.
\end{abstract}

$\mathrm{H}$

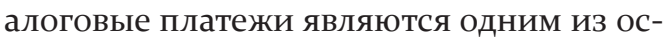
новных источников пополнения бюджетов всех уровней. Объем их поступления зависит от многих факторов: проводимой налоговой политики; развития экономики, в том числе, состояния предпринимательской деятельности; самосознания налогоплательщиков, которое напрямую связано с пониманием ими необходимости уплачивать законно установленные платежи, на что в немалой степени оказывает влияние справедливость последующего распределения бюджетных средств и т.д.

Во многом собираемость налогов зависит и от деятельности налоговых органов, призванных осуществлять постоянный контроль за исполнением налогового законодательства.

Закон предоставляет налоговым органам достаточно широкие полномочия с целью выявления нарушений, допускаемых налогоплательщиком, и применения принудительных мер в тех случаях, когда недобросовестные налогоплательщики отказываются добровольно заплатить налоговую задолженность.

Налоговый кодекс РФ (далее - НК РФ) определяет порядок привлечения таких налогоплательщиков к ответственности, предусмотренной налоговым и административным законодательством, а также процедуру направления материалов в следственные органы для решения вопроса о возбуждении уголовного дела в тех случаях, когда размер недоимки позволяет предполагать факт совершения налогового правонарушения, содержащего признаки преступления (п. 3 ст. 32 НК РФ). К таким признакам, в частности, относится обязательный размер недоимки, соответствующий примечаниям к ст. 198 и 199 УК РФ.

До недавнего времени единственным поводом для возбуждения уголовного дела о налоговом преступлении по ст. 198-199.2 УК РФ являлись материалы, которые направлялись налоговыми органами в Следственный Комитет РФ в порядке п. 3 ст. 32 НК РФ. Такой порядок был введен Федеральным законом от 06.12.11 № 407-ФЗ. Тем самым была поставлена точка в длительных спорах о возможности возбуждения уголовных дел по данным статьям не только по материалам налоговых органов, но и органов МВД.

Федеральным законом от 22.10.2014 № 308-ФЗ в ст. 140 и 144 УПК РФ были внесены существенные изменения, позволяющие возбуждать уголовные дела о налоговых преступлениях без проведения налоговой проверки в рамках налогового законодательства и наличия решения налогового органа, свидетельствующего о наличии у налогоплательщика недоимки. Основной причиной нововведения явилось резкое снижение числа возбужденных уголовных дел о налогах и, соответственно, — возмещаемых сумм ущерба, причиняемого данными преступлениями.

Авторы указанных новелл действующего законодательства рассчитывали, видимо, на изменение сложившейся ситуации с выявлением и результатами расследования налоговых преступлений. Между тем, для понимания и осознания причин возникших проблем, связанных с неудовлетворительным состоянием процесса привлечения к уголовной ответственности недобросовестных налогоплательщиков, необходимо вспомнить историю развития законодательства в этой части.

До введения в действие части первой НК РФ в 1998 г. налоговые органы проводили контрольные мероприятия в целях уплаты налоговых платежей в соответствии с Законом РФ «О налоговой системе Российской Федерации», которым были определены основные права и обязанности должностных лиц данных органов. Параллельно осуществляли свою деятельность органы налоговой полиции на основании Закона РФ от 24.06.1993 № 5238-1 «О федеральных органах налоговой полиции», в соответствии со ст. 11 которого, помимо специфических полномочий, свойственных правоохранительным органам, на них распространялись права 
налоговых органов. В частности, они могли пользоваться при исполнении служебных обязанностей правами, предоставленными должностным лицам налоговых органов и агентам валютного контроля; осуществлять при наличии достаточных данных проверки налогоплательщиков (в том числе контрольные проверки после проверок, проведенных налоговыми органами) в полном объеме с составлением актов по результатам этих проверок и принятием решений по актам проверок и применением соответствующих санкций; приостанавливать операции налогоплательщиков по счетам в банках и кредитных учреждениях на срок до одного месяца в случаях непредставления документов, связанных с исчислением и уплатой налогов.Установив нарушения налогового законодательства, содержащие признаки преступления, органы налоговой полиции привлекали виновных к уголовной ответственности.

Данный порядок был изменен в связи с принятием в 1998 г. части первой НК РФ. Так, ст. 7 Федерального закона от 31.07.1998 № 147-ФЗ «О введении в действие Налогового кодекса Российской Федерации» констатировала, что федеральные законы и иные нормативные правовые акты, действующие на территории РФ, не вошедшие в перечень актов, утративших силу в связи с принятием данного закона, действуют в части, не противоречащей части первой НК РФ, и подлежат приведению в соответствие с ней. Данный закон вступил в силу с 3 августа 1998 г., а НК РФ, за некоторыми исключениями, - с 1 января 1999 г.

Таким образом, с даты начала действия части первой НК РФ полномочия должностных лиц органов налоговой полиции должны были соответствовать положениям НК РФ, которые в корне отличались от того, что было установлено в Законе РФ «О федеральных органах налоговой полиции». Согласно НК РФ (ст. 31 в первоначальной редакции) только налоговым органам предоставлялось право проводить налоговые проверки.Органы налоговой полиции в соответствии со ст. 36 НК РФ должны были выполнять только функции по предупреждению, выявлению, пресечению и расследованию нарушений законодательства о налогах и сборах, являющихся преступлениями или административными правонарушениями. В том случае, когда должностные лица органов налоговой полиции выявляли обстоятельства, требующие совершения действий, отнесенных НК РФ к полномочиям налоговых органов, они были обязаны в трехдневный срок направить соответствующие материалы в налоговый орган для принятия по ним решения (п. 3 ст. 36 НК РФ в той же редакции). Участвовать в налоговых проверках они могли лишь по запросу налоговых органов (п. 2 ст. 36 НК РФ в той же редакции).

После принятия части первой НК РФ возникло немало проблем, так как формулировка ст. 36
НК РФ вошла в противоречие со ст. 11 Закона РФ «О федеральных органах налоговой полиции», которая так и не была изменена должным образом.

Такое положение порождало у следователей, прокуроров и судей, рассматривающих уголовные дела о налоговых преступлениях, различное понимание легитимности результатов деятельности органов налоговой полиции, продолжавших проводить налоговые проверки, по результатам которых возбуждались уголовные дела. Так продолжалось в течение года, в результате чего некоторыми судами выносились оправдательные приговоры на основании того, что факт наличия недоимки у налогоплательщика не был установлен налоговым органом, являвшимся единственным, кто обладал такими полномочиями. Кроме того, нередко адвокаты в суде предоставляли сведения о том, что в противовес выводам проведенной органом налоговой полиции проверки, выявившей факт недоимки по конкретной сделке за определенный налоговый период, по результатам выездной налоговой проверки, проведенной налоговым органом за тот же самый период, налоговая задолженность у налогоплательщика отсутствовала.

Федеральным законом от 02.01.2000 № 13-ФЗ п. 2 ст. 36 НК РФ был дополнен подп. 5, в соответствии с которым органам налоговой полиции при наличии достаточных данных, указывающих на признаки преступления, предоставлялось право производить проверки в соответствии с законодательством РФ. По результатам данной проверки они были вправе составлять акт о проверке налогоплательщика, на основании которого решать вопрос о возбуждении уголовного дела, об отказе в возбуждении или о направлении материалов в налоговый орган (при наличии налогового правонарушения и отсутствии признаков состава преступления). С момента устранения данного противоречия законов проблемы законности выявленных нарушений органами налоговой полиции сами собой отпали. Такой порядок просуществовал вплоть до ликвидации в 2003 г. органов налоговой полиции и передачи полномочий по расследованию уголовных дел о налоговых преступлениях органам МВД, в которых были созданы специализированные подразделения по выявлению налоговых должников, в действиях которых имелись признаки преступления.

Одновременно с ликвидацией органов налоговой полиции в ст. 36 НК РФ вновь были внесены изменения, в соответствии с которыми органы внутренних дел могли участвовать в выездных налоговых проверках только по запросу налоговых органов и исключительно вместе с ними. При выявлении обстоятельств, требующих совершения действий, отнесенных НК РФ к полномочиям налоговых органов, органы внутренних дел обязаны были в десятидневный срок со дня выявления указанных обстоятельств на- 
править материалы в соответствующий налоговый орган для принятия по ним решения. Кроме того, в соответствии со ст. 37 НК РФ органы внутренних дел несли ответственность за убытки, причиненные налогоплательщикам, вследствие своих неправомерных действий (решений) или бездействия, а равно неправомерных действий (решений) или бездействия должностных лиц и других работников этих органов при исполнении ими служебных обязанностей. Таким образом, как и ранее, наличие недоимки у налогоплательщика согласно НК РФ вправе был выявить только налоговый орган, на который и была возложена данная обязанность и оформление соответствующих документов с точным соблюдением процедуры, установленной НК РФ.

Федеральным законом от 30.06.2003 № 86-ФЗ ст. 11 Закона РФ от 18.04.1991 № 1026-1 «О милиции» была дополнена п. 33 - о праве органов МВД участвовать в налоговых проверках по запросу налоговых органов; п. 34, в соответствии с которым органы МВД могли получать сведения, составляющие налоговую тайну, соблюдая законодательство РФ; а также п. 35, установившим, что при наличии достаточных данных, указывающих на признаки преступления, связанного с нарушением законодательства РФ о налогах и сборах, органы МВД могли проводить проверки организаций и физических лиц в соответствии с законодательством РФ.

Выделив в ст. 11 Закона РФ «О милиции» специальные пункты, касающиеся проведения проверок соблюдения именно налогового законодательства, остальные права органов МВД, перечисленные в данной норме, нельзя было распространять на проверки, проводимые у налогоплательщиков. То есть права органов МВД в данной части были строго ограничены. Налоговый кодекс РФ также не предусматривал возможности проведения органами МВД налоговых проверок. Таким образом, в результате изменений законодательства вновь встал вопрос о легитимности выводов органов МВД по результатам проводимых ими проверок о наличии нарушений, свидетельствующих о признаках налогового преступления. Из содержания п. 35 ст. 11 Закона РФ «О милиции» явствовало, что под законодательством, которое в нем упоминалось, подразумевался Закон РФ «Об оперативно-розыскной деятельности», дававший право органам МВД проводить проверки налогоплательщиков, так как только он не ограничивал данные органы в объектах проверок. Но факты выявленных нарушений в рамках данного закона не увязывались с правомочиями налогоплательщиков, предоставленных им НК РФ, об оспаривании фактов установления у них недоимки в том случае, когда они не были согласны с мнением органов МВД. Это шло в разрез с общей концепцией налогового законодательства, которое предостав- ляло возможность обжаловать действия налогового органа, проводившего проверки, в том числе, и в судебном порядке. В связи с этим представляется совершенно логичной последующая отмена в 2008 г. п. 35 ст. 11 Закона РФ «О милиции»'. В соответствии с данными изменениями, внесенными в закон, далее совместными приказами МВД и МНС России был принят ряд инструкций, регламентирующих порядок взаимодействия данных органов при выявлении налоговых правонарушений и направлении материалов друг другу (аналогично с тем, что происходит и в настоящее время).

Особый интерес представляет собой Инструкция о порядке проведения проверок организаций и физических лиц при наличии достаточных данных, указывающих на признаки преступления, связанного с нарушениями законодательства РФ о налогах и сборах, утвержденная приказом МВД РФ от 16.03.2004 № 177. Согласно данной инструкции проверки должны были проводиться сотрудниками подразделений органов внутренних дел по налоговым преступлениям, в должностные обязанности которых входило предупреждение, пресечение, выявление и документирование соответствующих преступлений и административных правонарушений. В случае необходимости проведения в ходе проверки осмотра производственных, складских, торговых и иных служебных помещений, других мест хранения и использования имущества, досмотра транспортных средств, изучения документов, отражающих финансовую, хозяйственную, предпринимательскую и торговую деятельность, изъятия отдельных образцов сырья, продукции и товаров, соответствующие действия должны были осуществляться в порядке, установленном п. 25 ч. 1 ст. 11 Закона РФ «О милиции». По итогам проверки должен был составляться акт, в итоговой части которого отражались обобщенные сведения о результатах проверки с указанием нормативных правовых актов, нарушения положений которых выявлены. По результатам проверки организации или физического лица составлялся рапорт об обнаружении признаков преступления с последующим принятием решения в порядке, предусмотренном ст. 144 и 145 УПК РФ и материалы проверки направлялись следователям для решения вопроса о возбуждении уголовного дела. При отсутствии признаков налогового преступления материалы рассматривались в рамках производства по делам об административных правонарушениях. В случае выявления обстоятельств, требующих совершения действий, отнесенных к полномочиям налоговых органов,

\footnotetext{
Федеральный закон от 26.12.2008 № 293-Ф3 «О внесении изменений в отдельные законодательные акты Российской Федерации в части исключения внепроцессуальных прав органов внутренних дел Российской Федерации, касающихся проверок субъектов предпринимательской деятельности».
} 
принималось решение о передаче материалов в налоговые органы. Если никаких нарушений не выявлялось, то составлялся акт о завершении проверки в связи с неустановлением нарушений законодательства РФ.

Вынужденность принятия данных инструкций объясняется общей непродуманностью действовавшего на тот период законодательства, нестыковкой положений НК РФ в части процедуры проведения налоговых проверок и полномочий налоговых органов с иными законами, регламентировавшими порядок проведения проверок правоохранительными органами по выявлению преступлений. Данная инструкция (ведомственный акт), по существу, подменяла собой закон НК РФ, являющийся специальным относительно других законов в сфере налогообложения, и имела расширительное толкование, касающееся полномочий должностных лиц МВД РФ. На практике вновь возникли те же проблемы, что и в период изменения полномочий органов налоговой полиции в связи с принятием части первой НК РФ, результатом чего была последующая реорганизация органов МВД и упразднение специализированных подразделений, занимавшихся выявлением налоговых преступлений, использовавших полномочия, несоответствовавшие действовавшему в тот период законодательству.

Федеральным законом от 29.12.2009 № 383-ФЗ были внесены существенные изменения в НК РФ, УК РФ, УПК РФ, касающиеся упорядочения положений действующего законодательства в части урегулирования полномочий должностных лиц налоговых органов и органов МВД РФ, используемых ими в сфере налогообложения.

Анализ совокупности этих и последующих изменений, вносимых в законы, позволяет сделать вывод о том, что законодателем были определены главные цели специального контролирующего органа, отвечающего за сбор налогов, и следственных органов, призванных осуществлять борьбу с лицами, совершившими преступление. Об этом могут свидетельствовать такие новеллы закона, как: значительное увеличение срока (до 2 месяцев), в течение которого налогоплательщик может добровольно погасить налоговую задолженность, и до истечения которого налоговый орган не правомочен направить соответствующие материалы в следственные органы для возбуждения уголовного дела; от 10 до 30 раз увеличенная сумма недоимки, при наличии которой лицо может быть привлечено к уголовной ответственности по ст. 198 или 199 УК РФ; отмена применения за совершение данных преступлений такой меры пресечения, как заключение под стражу; обязанность следователя прекратить уголовное дело в случае добровольной уплаты подозреваемым или обвиняемым суммы налоговой задолженности на предварительном следствии и др.
Представляется, что данные изменения закона имели четкую направленность на активизацию деятельности налоговых органов, имеющих специальные полномочия, установленные налоговым законодательством, с целью обеспечения своевременного и полного поступления налогов в бюджет, а не на запугивание налогоплательщиков привлечением к уголовной ответственности (приводящее, скорее, не к увеличению бюджетных доходов за счет налоговых платежей, а к финансовым затратам на деятельность государственных органов).

Трудно не согласиться с мнением некоторых авторов, что по замыслу законодателя уголовная ответственность должна была наступать только при наличии обстоятельств, свидетельствующих о нежелании виновного лица отказаться от противоправных действий по уклонению от уплаты налогов, и только за те правонарушения, которые имели большую общественную опасность²

Приведенный выше исторический обзор изменений законодательства, касающихся полномочий различных органов, наглядно демонстрирует отсутствие общего логического подхода к тому, кто с кем борется, пытаясь собрать налоги, и какова конечная цель этой борьбы.

Вновь внесенные изменения в ст. 140 УПК РФ восстановили по существу уже неоднократно неудачно использованную систему о порядке возбуждения уголовных дел о налоговых преступлениях. Законодатель попытался соединить нормы уголовно-процессуального и налогового законодательства, предусмотрев несколько вариантов возможных взаимоотношений между правоохранительными и налоговыми органами при выявлении признаков преступления. Органам МВД и СК РФ предоставлено право проверки поступивших к ним сведений о фактах преступного уклонения от налогов, но в соответствии с п. 1-3 ч. 8 ст. 140 УПК РФ они должны получать определенные сведения (сообщения или заключения) из налоговых органов о проводимых ими проверках в отношении конкретного налогоплательщика, после чего принимать решение о возбуждении уголовного дела. Часть 9 данной нормы позволяет возбудить уголовное дело и без получения необходимых данных из налогового органа. Только непонятно, что должен дальше делать следователь при отсутствии своевременно проведенной налоговой проверки налоговым органом? Сколько еще раз нужно наступить на те же грабли, чтобы убедиться в бесполезности односторонних изменений и дополнений только уголовно-процессуального закона? Когда правоприменителям и законодателям станет понятно,

См.: Александров А.С., Пятышев Я.С., Горюнов В.Ю. Кризис правового механизма уголовного преследования по делам о налоговых преступлениях // Мировой судья. 2013. № 12. 
что результат борьбы с неплательщиками налогов зависит не только от процедуры возбуждения уголовного дела?

Причин значительного снижения количества уголовных дел о налоговых преступлениях, доведенных до суда, несколько, среди которых можно выделить основные.

Первая группа носит субъективный характер. Так, следователи часто не регистрируют материалы, поступившие из налоговых и правоохранительных органов под предлогом недостаточности поступивших документов, и возвращают их обратно; проводят поверхностные процессуальные проверки без установления всех имеющих значение факторов для принятия объективного решения, в связи с чем прокурорами ежегодно отменяется порядка 30\% постановлений об отказе в возбуждении уголовного дела. Имеют место случаи незаконного вынесения органами МВД постановлений об отказе в возбуждении уголовного дела в нарушение подследственности. В 2014 г. и 1 квартале 2015 г. прокурорами отменено 50\% таких решений. Половина из оконченных уголовных дел прекращена, из них - всего 15\% по ст. 28.1 УПК РФ, а 7о\% - за сроком давности.

Непринятие мер к розыску имущества налогоплательщика, за счет которого должна возмещаться налоговая задолженность, приводит к тому, что на досудебной стадии в 2014 г. и 1 квартале 2015 г. был возмещен ущерб всего по 31\% уголовных дел. В 2014 г. при ущербе в 67800 млн руб. арестовано имущество всего на 4289 млн руб., а в 1 квартале 2015 г. арест наложен на сумму 1526 млн руб. при ущербе в 6124 млн руб.

Прокурорами выявляются также случаи необоснованного отказа в возбуждении уголовного дела из-за отсутствия, по мнению следователя, признаков преступления; направления поступивших материалов без их регистрации в следственные органы, расположенные на других территориях; регистрации материалов, поступивших из налоговых органов, о решении вопроса по ст. 144, 145 УПК РФ при неуплате только пени и штрафа, когда налог фактически уплачен; прекращения уголовных дел по ст. 28.1 УПК РФ при уплате налогоплательщиком только суммы недоимки

Несвоевременность изъятия документов, необходимых для расследования налогового преступления и неумение доказывать наличие умысла в действиях лиц, привлекаемых к уголовной ответственности, приводит к несоблюдению разумных сроков расследования и последующего прекращения уголовных дел за истечением срока давности привлечения к уголовной ответственности.

\footnotetext{
См.: Информационное письмо заместителя Генерального прокурора от 29.06.2015 № 36-11-2015 «О состоянии законности при расследовании уголовных дел о налоговых преступлениях и практики прокурорского надзора за данной деятельностью».
}

Вторая группа причин возникла непосредственно из-за несовершенства и несогласованности действующего законодательства, не имеющего общих целей и задач в области налогообложения. Представляется, что конечным результатом деятельности и налоговых, и правоохранительных органов в данном случае является реальное поступление налоговой задолженности в бюджет и применение таких мер наказания, которые также влияли бы на финансовое положение налогоплательщика.

Безусловно, весьма существенным дополнением для решения данной задачи является дополнение УПК РФ ст. 16о.1, согласно которой теперь на следователя и дознавателя возложена именно обязанность принятия обеспечительных мер с целью возмещения ущерба, причиненного преступлением. Однако, самостоятельно, без участия органов, осуществляющих оперативно-розыскную деятельность, установить соответствующее имущество не представляется возможным.

В соответствии с Федеральным законом от 12.08.1995 № 144-Ф3 «Об оперативно-розыскной деятельности» обязанность по розыску имущества, возложенная на оперативных сотрудников, относится только к тому имуществу, которое имеет взаимосвязь с терроризмом или в отношении которого может быть применена конфискация. Однако в отношении имущества, за счет которого может быть возмещен ущерб и взыскана санкция в виде штрафа, такой обязанности нет.

В настоящее время активно обсуждается вопрос о введении в уголовное законодательство ответственности юридических лиц за совершение преступления. Представляется целесообразным дискутировать не об уголовной ответственности юридических лиц вообще, а лишь по отдельным бланкетным нормам УК РФ. Учитывая специфику именно налоговых преступлений, предмет доказывания по которым устанавливается непосредственно исходя из норм налогового законодательства, целесообразно предусмотреть в уголовно-процессуальном законе (одновременно внеся соответствующие изменения и дополнения в УК РФ), процедуру привлечения к уголовной ответственности юридических лиц, разделив ее с процедурой привлечения к ответственности руководителей организаций (главных бухгалтеров), определив субъектов и пределы материальной ответственности каждого из них за совершенное преступление.

При этом изменения в УПК РФ и УК РФ должны согласовываться с нормами НК РФ и полномочиями налоговых органов по взысканию налоговой задолженности. Наиболее оптимальной при этом видится схема, при которой независимо от возбуждения уголовного дела по ст. 199 УК РФ налоговые органы обязаны применять механизм бесспорного (безакцепного) взыскания задолженности в соответствии со ст. 46-47 НК РФ в от- 
ношении юридического лица, а также обеспечительные меры в соответствии с п. 10 ст. 101 НК РФ. В том случае, если у юридического лица (организации) отсутствуют средства, за счет которых может быть погашена задолженность и к этому процессу причастно лицо, привлекаемое к уголовной ответственности по ст. 199-199.2 УК РФ, то ущерб может взыскиваться и с этого лица.

Серьезным препятствием для возбуждения и расследования налоговых преступлений является действующая формулировка ст. 90 УПК РФ, определившая преюдицию обстоятельств, установленных не только вступившим в законную силу приговором, но и иными вступившими в законную силу решениями суда, принятыми в рамках гражданского, арбитражного или административного судопроизводства, что вынуждает суд, прокуроров, следователей, и дознавателей признавать их без дополнительной проверки.

Внешне кажется, что положения ст. 140 и 144 УПК РФ, позволившие возбуждать уголовные дела без материалов налогового органа, решают проблему. Между тем, никто не отменял право налогоплательщика обращаться в суд об оспаривании решений налогового органа, без которого, как представляется, и в рамках действующей формулировки ст. 140 УПК РФ следователь вряд ли обойдется при расследовании уже возбужденного уголовного дела. В данном случае еще больше могут затянуться сроки расследования. Конечно, можно ставить вопрос о приостановлении рассмотрения арбитражного спора до окончания расследования и рассмотрения уголовного дела судом, чтобы его решение стало преюдициальным. Время покажет насколько применима данная законодательная процессуальная схема.

Опасность связана с тем, что налогоплательщик, как правило, оспаривает законность решения налогового органа в части сумм недоимок и доначисленных ему платежей. Одним из обязательных элементов предмета доказывания по уголовным делам о налоговых преступлениях является наличие крупного или особо крупного размера неуплаченных платежей, предусмотренного примечаниями к ст. 198, 199 УК РФ.

В случае возбуждения уголовного дела по данным статьям УК РФ и последующим проведением налоговой проверки, вынесение арбитражным судом решения об отмене решения налогового органа в связи с неправильностью определения размера неуплаченной суммы налога, должно одновременно являться основанием для прекращения уголовного дела, независимо от результатов, полученных в ходе следствия.

Кроме того, арбитражные суды приостанавливают реализацию обеспечительных мер, принятых налоговыми органами в рамках НК РФ, что дает возможность налогоплательщику скрыть имущество, за счет которого возможно взыскать налоговую задолженность.
Имеют место случаи, когда налогоплательщик в период приостановления судом решения налогового органа, направляет в арбитражный суд заявление о признании себя банкротом, что также может являться препятствием для направления налоговым органом материалов проверки в СК РФ в порядке ст. 144, 145 УПК РФ.

Указанные правила делают практически бессмысленным все усилия следователя, возбудившего уголовное дело, но зависящего от результата рассмотрения гражданского дела судом, которое в большинстве случаев затягивается на длительные сроки, в том числе, и в результате умышленных действий недобросовестных налогоплательщиков. С другой стороны, налоговые органы, не зная, признает ли арбитражный суд их решение законным, не во всех случаях, подпадающих под обязанность направления материалов проверки в СК РФ, делают это. Также, учитывая тот факт, что налоговые проверки проводятся за три года, предшествующих текущему году, могут истечь сроки давности привлечения к уголовной ответственности за совершение налогового преступления, даже в тех случаях, когда решение налогового органа будет признано законным.

Исходя из вышеизложенного, в ст. 90 УПК РФ необходимо внести изменения. Преюдиция не должна автоматически распространяться на обстоятельства, установленные арбитражным судом, так как их следует проверять следственным путем для обоснования выводов следователя о наличии или отсутствии признаков налогового преступления. В формулировке ст. 90 УПК РФ должно найти свое отражение мнение Конституционного Суда РФ по данному вопросу, выраженное им в постановлении от 21.12.2011 № $30-П$ «По делу о проверке конституционности положений статьи 90 Уголовно-процессуального кодекса Российской Федерации в связи с жалобой граждан В.Д. Власенко и Е.А. Власенко».

Необходимо обратить внимание и на то, что до последних изменений, внесенных в ст. 28.1 УПК РФ Федеральным законом от 07.12.2011 № 420-Ф3, ее содержание обязывало следователя в императивной форме прекратить уголовное преследование о налоговом преступлении, если подозреваемый или обвиняемый по уголовному делу полностью возместит ущерб в сумме неуплаченных им ранее недоимки, пени и штрафной санкции. В настоящее время в данную норму внесено дополнение, в соответствии с которым следователь при вышеперечисленных обстоятельствах прекращает уголовное преследование с согласия руководителя следственного органа. Данное дополнение внесло неясность в вопрос о том, во всех ли случаях возмещения ущерба подозреваемым или обвиняемым должно даваться разрешение руководителем следственного органа на прекращение уголовного преследования или его решение зависит еще от чего- 
то. В статье должны быть отражены условия, в силу которых руководитель следственного органа может не согласиться с прекращением уголовного преследования в отношении лица, полностью возместившего налоговую задолженность.

Не вполне понятна также логика законодателя, установившего, что в случаях полного возмещения ущерба до назначения судебного заседания уголовное преследование прекращается при наличии оснований, предусмотренных ст. 24 и 27 УПК РФ или ч. 1 ст. 76.1 УК РФ. Необходимо, видимо, уточнение о том, что в результате возмещения ущерба будет отсутствовать событие или состав преступления? То есть, можно считать, что уголовное преследование прекращено по реабилитирующим основаниям, а не по специально введенной норме - ст. 28.1 УПК РФ? Данная норма явно требует дополнительной правки.

Почему в данной статье сделана ссылка еще и на ст. 76.1 УК РФ, предусматривающую, что лицо, впервые совершившее преступление, предусмотренное ст. 198-199.1 УК РФ (чего нет в случае применения ст. 24, 27 УПК РФ), освобождается от уголовной ответственности, если ущерб, причиненный бюджетной системе РФ в результате преступления, возмещен в полном объеме? Видимо, это относится к тем случаям, когда сумма ущерба возмещена уже непосредственно в суде, но тогда данное основание может быть применено только судом, а не следователем.

Также ст. 28.1 УПК РФ не увязана и с текстом примечаний к ст. 198, 199 УК РФ, которые предусматривают, что лицо освобождается от уголовной ответственности за совершение налогового преступления при условии возмещения ущерба только в том случае, если оно совершило налоговое преступление впервые. В ст. 28.1 УПК РФ, ссылающейся на прекращение уголовного преследования на основании ст. 24, 27 УПК РФ, такой оговорки нет, в связи с чем возникает полная неясность в порядке практического применения данных норм, несогласованных друг с другом.

Необходимо также в ч. 3 ст. 44 УПК РФ выделить пункт, в силу которого обязанность по предъявлению иска о взыскании налоговой задолженности будет возложена именно на прокурора, или дополнить ее возможностью предъявления таких исков налоговыми органами. Формулировка ч. 3 ст. 44 УПК РФ, действующая в настоящее время, воспринимается правоприменителями неоднозначно, несмотря на то что из содержания указанной нормы следует, что гражданским истцом по уголовному делу является лицо, которому непосредственно преступлением причинен ущерб, или прокурор. На практике иски в уголовном деле предъявляются иногда налоговыми органами, однако непосредственно им никакого ущерба неуплатой налогов не причиняется, они лишь контролируют поступление налогов в бюджет. Налоговые органы могут применять право на предъявление иска только в рамках НК РФ непосредственно после проведенной налоговой проверки. Прокурор является единственным процессуальным лицом, правомочным в данном случае защищать интересы государства в части защиты его бюджетных отношений, как на федеральном, так и на региональном или муниципальном уровне.

Необходимо также уточнить, в каких случаях за налоговые преступления, предусмотренные ст. 199 УК РФ, может быть предъявлен иск прокурором в рамках уголовного дела о взыскании суммы недоимки и пени к обвиняемому - руководителю или главному бухгалтеру юридического лица, так как в соответствии с НК РФ налогоплательщиком в этом случае является организация, и именно в отношении нее налоговый орган применяет принудительные меры по взысканию задолженности.

Представляется, что для эффективного результата расследования уголовных дел о налоговых преступлениях, которым может считаться только реальное поступление в соответствующий уровень бюджета сумм налоговой задолженности, необходимо расширение перечня норм УК РФ, предусматривающих ответственность за налоговые преступления.

Отдельной статьей должны квалифицироваться действия, наносящие ущерб государственной казне при возмещении сумм НДС, с учетом того, что в подобных случаях не всегда происходит непосредственное уклонение от уплаты налога, а в зависимости от используемой преступной схемы, налогоплательщику предоставляется налоговый вычет или из бюджета на его счет перечисляются суммы в качестве возмещения ранее уплаченных сумм НДС, что, как правило, квалифицируется по ст. 159 УК РФ (мошенничество).

Некоторые налоговые преступления совершаются с помощью заключения фиктивных сделок, в результате чего бюджет также не получает «должное» в значительных суммах, но такой способ уклонения от уплаты налогов не предусмотрен ст. 198, 199 УК РФ.

При внесении изменений в законодательство, предусматривающее уголовную ответственность за совершение налоговых преступлений, следует учесть наиболее распространенные схемы уклонения от уплаты налогов, за которые невозможно в настоящее время привлечь к уголовной ответственности, так как УК РФ не предусмотрены соответствующие способы уклонения от уплаты налогов, несмотря на то что государству при этом причиняется значительный ущерб.

Можно предусмотреть и дополнительные меры наказания, например, по аналогии с законодательством других зарубежных стран, - установление запрета лицам, уклонившимся от уплаты 
прямых налогов, НДС и др., на профессиональную деятельность в течение трех лет, а в случае рецидива увеличение этого срока вдвое.

Весьма продуманным условием, применяющимся в некоторых странах Восточной Европы, является то, что в случае возмещения обвиняемым налогового долга до окончания рассмотрения дела в суде, он освобождается от уголовной ответственности не полностью, к такому лицу не применяется лишение свободы, но налагается денежный штраф. Таким образом, лицо, совершившее преступление, хотя и загладившее причиненный вред, в любом случае несет наказание, но значительно меньшее по сравнению с тем, которое оно могло бы получить. Это положение имеет глубокий смысл и во многом способствует предупреждению налоговых преступлений. Налогоплательщик, уклоняющийся от выполнения обязанности по уплате налоговых платежей, заведомо знает о том, что при выявлении его преступных действий наказание неизбежно (в отличие от законодательства, действующего в России).

Было бы логичным ввести специализацию следователей, судей, рассматривающих преступления в области экономики, к которым необходимо применить требование об обязательном наличии у них юридического и экономического образования.

Что касается возможности возбуждения уголовных дел о налоговых преступлениях не только по материалам налоговых органов, но и органов МВД, то одновременно должны быть внесены соответствующие изменения в НК РФ, предоставляющие полномочия органам МВД РФ по проведению проверок налогоплательщиков и принятию по ним соответствующих решений, т.е. сделать данные органы легитимными в сфере на- логообложения. В противном случае нарушаются законные права налогоплательщика, так как без проведения налоговой проверки в соответствии с НК РФ и наличия решения по ее результатам руководителя налогового органа налогоплательщик лишен возможности возместить всю налоговую задолженность, состоящую из недоимки, пени и штрафной санкции, которые могут назначить только должностные лица налоговых органов. В результате в отношении такого налогоплательщика не могут быть применены положения ст. 28.1 УПК РФ, согласно которой уголовное дело прекращается только при возмещении всей суммы налоговой задолженности.

В целом же, представляется, что наибольшего результата в борьбе с налоговыми правонарушениями и преступлениями можно было бы достичь полным изменением концепции действующего законодательства в рассматриваемой сфере, предусмотрев широкий спектр правовых норм, устанавливающих адекватные санкции за данные преступления.

\section{Список литературы}

1. Актуальные проблемы обеспечения законности в налоговой сфере // Сборник научных трудов. М.: НИИ проблем укрепления законности и правопорядка при ГП РФ, 2005.

2. Никифоров А.В. Полномочия налоговых органов при применении ответственности за налоговые преступления // Административное и муниципальное право. 2013. № 11.

3. Александров А.С., Горюнов В.Ю., Пятышев Я.С. Кризис правового механизма уголовного преследования по делам о налоговых преступлениях // Мировой суДья. 2013. № 12 .

4. Искаков С.Е. Проблемы применения норм о налоговых преступлениях // Юридический мир. 2013. № 10.

5. Левченко О.В. Практика расследования налоговых преступлений // Московский юрист. 2013. № 2.

\title{
The problem of attracting to criminal liability for committing tax crimes
}

\author{
Titova V.N., \\ $\mathrm{PhD}$ in Law, Associate Professor, \\ Professor of the Department of Prosecutor's Supervision over Observance of Laws \\ in the Operational-Search Activity and Participation of the Prosecutor in Criminal Proceedings \\ of the Academy of the Prosecutor General of the Russian Federation \\ E-mail: vt3013607@yandex.ru
}

Abstract. The article discusses the reasons for the significant reduction of criminal cases on tax crimes in the court with the indictment and the low level of compensation for this category of crimes, made concrete proposals for improving the existing legislation to change the situation.

Keywords: tax authorities, the investigator, tax and criminal law, damages, the Prosecutor, the change in the concept of legislation in the sphere of taxation.

\section{References}

1. Aktual'nye problemy obespecheniya zakonnosti v nalogovoi sfere // Sbornik nauchnyh trudov. M.: NII problem ukrepleniya zakonnosti i pravoporyadka pri GP RF, 2005.

2. Nikiforov A.V. Polnomochiya nalogovyh organov pri primenenii otvetstvennosti za nalogovye prestupleniya // Administrativnoe i municipal'noe pravo. 2013. № 11.

3. Aleksandrov A.S., Goryunov V.Yu., Pyatyshev Ya.S. Krizis pravovogo mehanizma ugolovnogo presledovaniya po delam o nalogovyh prestupleniyah // Mirovoi sud'ya. 2013. № 12.

4. Iskakov S.E. Problemy primeneniya norm o nalogovyh prestupleniyah // Yuridicheskii mir. 2013. № 10.

5. Levchenko O.V. Praktika rassledovaniya nalogovyh prestuplenii // Moskovskii yurist. 2013. № 2. 